Pacific Journal of Mathematics

A CHARACTERIZATION OF DIMENSION OF TOPOLOGICAL
SPACES BY TOTALLY BOUNDED PSEUDOMETRICS 


\title{
A CHARACTERIZATION OF DIMENSION OF TOPOLOGICAL SPACES BY TOTALLY BOUNDED PSEUDOMETRICS
}

\author{
JEROEN BRUIJNING
}

\begin{abstract}
For a compact metrizable space $X$, for a metric $d$ on $X$, and for $\varepsilon>0$, the number $N(\varepsilon, X, d)$ is defined as the minimum number of sets of $d$-diameter not exceeding $\varepsilon$ required to cover $X$. A classical theorem characterizes the topological dimension of $X$ in terms of the numbers $N(s, X, d)$. In this paper, two extensions of this result are given: (i) a direct one, to separable metrizable spaces, involving totally bounded metrics; (ii) a more complicated one, involving the set of continuous totally bounded pseudometrics on the space as well as a special order on this set.
\end{abstract}

The dimension function involved is the so-called Katètov dimension, i.e., covering dimension with respect to covers by cozero sets. Let $d$ be a metric for the compact metrizable space $X$. Define

$$
k(X, d)=\sup \left\{\inf \left\{-\frac{\log N(\varepsilon, X, d)}{\log \varepsilon} \mid \varepsilon<\varepsilon_{0}\right\} \mid \varepsilon_{0}>0\right\} .
$$

Then we have the classical

Theorem A (L. Pontrjagin and L. Schnirelmann [4]).

$$
\operatorname{dim} X=\inf \{k(X, d) \mid d \text { is a metric for } X\} \text {. }
$$

REMARK. The number $\log N(\varepsilon, X, d)$ is often referred to as the $\varepsilon / 2$-entropy of $X$ (with respect to $d$ ).

The extension of Theorem A to separable metrizable spaces is given by Theorem 2, while the general case is covered by Theorem 1. The referee has pointed out that Lemma 5 below, needed in the proof of Theorem 1, can be derived from two theorems by Katētov ([3], Theorems 1.9 and 1.16). The author wishes to thank Professor J. Nagata for drawing his attention to Theorem A and to the problem of finding its generalization.

2. Definitions and notations. All spaces considered will be nonempty. A zeroset (cozeroset) in a space $X$ is a set of the form $f^{-1}(\{0\})\left(f^{-1}((0,1])\right)$, where $f: X \rightarrow[0,1]$ is continuous. The symbols $U$, $U_{i}, V, V_{i}$, etc. will denote cozerosets throughout; $F, F_{i}, F_{j}^{k}$ etc. will denote zerosets. If $\mathscr{A}=\left\{A_{r} \mid \gamma \in \Gamma\right\}$ is a collection of subsets of $X$, the order of $\mathscr{A}$ (ord $\mathscr{A}$ ) is defined as $\sup \left\{\left|\mathscr{A}^{\prime}\right| \mid \mathscr{A}^{\prime} \subset \mathscr{A}\right.$ and 
$\left.\cap \mathscr{A}^{\prime} \neq \varnothing\right\} . \quad \operatorname{Dim} X$ will be the Katétov dimension of $X$, i.e., $\operatorname{dim} X \leqq n$ iff every finite cover $\mathscr{U}=\left\{U_{1}, \cdots, U_{k}\right\}$ has a finite refinement $\mathscr{V}=\left\{V_{1}, \cdots, V_{l}\right\}$ with ord $\mathscr{V} \leqq n+1$;

$\operatorname{dim} X=n$ iff $\operatorname{dim} X \leqq n$ but not $\operatorname{dim} X \leqq n-1 ;$ $\operatorname{dim} X=\infty$ iff $\operatorname{not} \operatorname{dim} X \leqq n$ for any $n$.

Note that in the above definition, $U_{i}$ and $V_{j}$ are cozerosets by notation. For normal spaces, Katêtov dimension coincides with ordinary covering dimension [1, p. 268].

A continuous pseudometric on a space $X$ is a continuous function $d: X \times X \rightarrow[0, \infty)$ which is symmetric, satisfies the triangle inequality and has the property that $d(x, x)=0$ for all $x \in X$. A pseudometric $d$ is totally bounded iff for every $\varepsilon>0$ there exists a finite $\varepsilon$-net in $X$ with regard to $d$. $\mathscr{R}$ will be the set of all totally bounded, continuous pseudometrics on $X$. For $d \in \mathscr{R}, \varepsilon>0$ and $x \in X, U_{\varepsilon}^{d}(x)$ is defined as the set $\{y \in X \mid d(x, y)<\varepsilon\}$. This is a cozeroset. On $\mathscr{R}$ we introduce the following relation: $d_{1}>d_{2}$ iff for all $\varepsilon>0$ there exists a $\delta>0$ such that $U_{\delta}^{d_{1}}(x) \subset U_{\varepsilon}^{d_{2}}(x)$ for all $x \in X$. For $d \in \mathscr{R}$ and $A \subset X$, the diameter of $A$ with regard to $d$ is the number $d$-diam $A=$ $\sup \{d(x, y) \mid x, y \in A\}$. We define $|d|=d$-diam $X .|d|$ is always finite. Finally, if $\mathscr{C}$ is a cover of $X$ and $d \in \mathscr{R}$, we say that $\mathscr{C}$ is $d$-uniform iff there exists $\varepsilon>0$ such that the cover $\left\{U_{\varepsilon}^{d}(x) \mid x \in X\right\}$ refines $\mathscr{C}$.

3. An extension of Theorem A. For $d \in \mathscr{R}$ and $\varepsilon>0$, let $N(\varepsilon, X, d)$ be defined as the minimum number of sets of $d$-diameter not exceeding $\varepsilon$ required to cover $X$. Put

$$
k(X, d)=\sup \left\{\inf \left\{-\frac{\log N(\varepsilon, X, d)}{\log \varepsilon} \mid \varepsilon<\varepsilon_{0}\right\} \mid \varepsilon_{0}>0\right\},
$$

just as in the introduction.

Then we have

THEOREM 1. If $k(X, d)$ is defined as above, then

$$
\operatorname{dim} X=\sup \left\{\inf \left\{k(X, d) \mid d \succ d_{0}, d \in \mathscr{R}\right\} \mid d_{0} \in \mathscr{R}\right\} .
$$

Before we give the proof, we will state and prove a few lemmas.

LEMMA 1. Let $\delta>0$, and let $\mathscr{C}=\left\{U_{1}, \cdots, U_{k}\right\}$ be a cover of $X$. Then there exists $d \in \mathscr{R}$ such that $\mathscr{U}$ is $d$-uniform and $|d| \leqq \delta$.

Proof. For the sake of completeness, we include an elementary proof. Let $f_{i}: X \rightarrow[0,1]$ be continuous, with $f_{i}^{-1}((0,1])=$ 
$U_{i}(1 \leqq i \leqq k)$

Define $f: X \rightarrow \boldsymbol{R}^{k}$ by the formula

$$
f(x)=\left(\frac{f_{1}(x)}{\sum_{i=1}^{k} f_{i}(x)}, \cdots, \frac{f_{k}(x)}{\sum_{i=1}^{k} f_{i}(x)}\right) .
$$

Define $d_{1}: X \times X \rightarrow[0, \infty)$ by $d_{1}(x, y)=\|f(x)-f(y)\|$. It is not difficult to show that $d_{1} \in \mathscr{R}$. Now

$$
f(X) \subset \Delta=\left\{\left(\lambda_{1}, \cdots, \lambda_{k}\right) \mid \sum_{i=1}^{k} \lambda_{i}=1 \quad \text { and } \quad \lambda_{i} \geqq 0(1 \leqq i \leqq k)\right\} .
$$

Denoting the set $\left\{\left(\lambda_{1}, \cdots, \lambda_{k}\right) \in \Delta \mid \lambda_{j}>0\right\}$ by $V_{j}$, we have $U_{j}=f^{-1}\left(V_{j}\right)$ $(1 \leqq j \leqq k)$. $\left\{V_{1}, \cdots, V_{k}\right\}$ is an open cover of the compact set $\Delta$, so there exists $\varepsilon>0$ such that the cover $\left\{U_{\varepsilon}(p) \cap \Delta \mid p \in \Delta\right\}$ refines $\left\{V_{1}, \cdots, V_{k}\right\}$. Let $x \in X$. Then there exists $j, 1 \leqq j \leqq k$, such that $U_{\varepsilon}\left((f(x)) \subset V_{j}\right.$. It follows that $U_{\varepsilon}^{d_{1}}(x) \subset f^{-1}\left(V_{j}\right)=U_{j}$. Thus $\mathscr{Q}$ is $d_{1}$-uniform. Finally putting $d=\delta /\left|d_{1}\right| \cdot d_{1}$ we get the desired element of $\mathscr{R}$.

Lemma 2. (a) Let $d_{1}, d_{2} \in \mathscr{R}$. Then $d_{1}+d_{2} \in \mathscr{R}$.

(b) Let $d_{i} \in \mathscr{R}(i \in N)$ and let $\sum_{i=1}^{\infty}\left|d_{i}\right|<\infty$. Then $\sum_{i=1}^{\infty} d_{i} \in \mathscr{R}$.

Proof. (a) It is easy to see that $d_{1}+d_{2}$ is a continuous pseudometric. To prove that is totally bounded, let $\varepsilon>0$ and $\left\{x_{1}, \cdots, x_{k}\right\}$ be an $\varepsilon / 3$-net for $\left(X, d_{1}\right)$. Let, for $1 \leqq i \leqq k,\left\{y_{1}^{i}, \cdots, y_{n_{i}}^{i}\right\}$ be an $\varepsilon / 3$ net for $U_{\varepsilon / 3}^{d_{1}}\left(x_{i}\right)$, with regard to $d_{2}$ (the restriction of $d_{2}$ to any subset of $X$ is again totally bounded, as can be proved in a standard manner). Put $Y=\left\{y_{j}^{i} \mid 1 \leqq i \leqq k, 1 \leqq j \leqq n_{i}\right\}$. It is not difficult to prove that $Y$ is an $\varepsilon$-net for $X$ with respect to $d_{1}+d_{2}$. This proves (a).

(b) $\sum_{i=1}^{\infty} d_{i}$ is, as a uniform limit of continuous functions, itself continuous. It is easily seen to be a pseudometric. Let $\varepsilon>0$, and $N \in N$ so, that $\Sigma_{i>N}\left|d_{i}\right|<\varepsilon / 2$. Since by (a), $\Sigma_{i=1}^{N} d_{i} \in \mathscr{R}$, there exists a finite $\varepsilon / 2$-net for $X$ with respect to $\sum_{i=1}^{N} d_{i}$. The same set is easily proved to be an $\varepsilon$-net for $\left(X, \sum_{i=1}^{\infty} d_{i}\right)$, which proves (b).

Lemma 3. Let $Y$ be a dense subset of $X$, and let $d \in \mathscr{R}$. Then $k(X, d)=k(Y, d \mid Y \times Y)$.

Proof. It is easy to see that $N(\varepsilon, X, d)=N(\varepsilon, Y, d \mid Y \times Y)$ for all $\varepsilon>0$. From this the result follows by the very definition of $k(X, d)$ and $k(Y, d \mid Y \times Y)$.

Now we are ready to go on with the proof of Theorem 1 . For shortness, denote $\sup \left\{\inf \left\{k(X, d) \mid d>d_{0}, d \in \mathscr{R}\right\} \mid d_{0} \in \mathscr{R}\right\}$ by $k(X)$. First we prove: $k(X) \geqq \operatorname{dim}(X)$. This will follow from the following 
Lemma 4 . Let $n \geqq 0$ and $\operatorname{dim} X \geqq n$. Then there exists $d_{0} \in \mathscr{R}$ such that, for all $d \in \mathscr{R}$ with $d>d_{0}, k(X, d) \geqq n$. (This formulation also takes care of the case $\operatorname{dim} X=\infty$.)

Proof of Lemma 4. Let $\mathscr{U}=\left\{U_{1}, \cdots, U_{k}\right\}$ be a cover such that every refinement $\mathscr{V}=\left\{V_{1}, \cdots, V_{l}\right\}$ of $\mathscr{\mathscr { C }}$ has order $\geqq n+1$. By Lemma 1 , there is a $d_{0} \in \mathscr{R}$ such that $\mathscr{Q}$ is $d_{0}$-uniform. Let $d \succ d_{0}$, $d \in \mathscr{R}$. Then there exists $\delta>0$ such that the cover $\left\{U_{\delta}^{d}(x) \mid x \in X\right\}$ refines $\mathscr{C}$.

Consider the equivalence relation $\sim$ on $X$ defined by $x \sim y$ iff $d(x, y)=0$. Let $X^{\prime}$ be the set of evuivalence classes, and $\phi: X \rightarrow X^{\prime}$ the natural projection. Define $d^{\prime}: X^{\prime} \times X^{\prime} \rightarrow[0, \infty)$ by $d^{\prime}(\phi(x), \phi(y))=$ $d(x, y)$. This definition turns $\left(X^{\prime}, d^{\prime}\right)$ into a totally bounded metric space. Since $d$ is continuous, $\phi$ is continuous if we equip $X^{\prime}$ with the metric topology. Furthermore, if $A \subset X$, then $d$-diam $A=$ $d^{\prime}$-diam $\phi(A)$; and if $B \subset X^{\prime}$, then $d^{\prime}$-diam $B=d$-diam $\phi^{-1}(B)$. It follows that $N(\varepsilon, X, d)=N\left(\varepsilon, X^{\prime}, d^{\prime}\right)$ for all $\varepsilon>0$, thus $k(X, d)=$ $k\left(X^{\prime}, d^{\prime}\right)$. Let $\left(X^{\prime \prime}, d^{\prime \prime}\right)$ be the metric completion of $\left(X^{\prime}, d^{\prime}\right)$. Since $\left(X^{\prime}, d^{\prime}\right)$ is totally bounded, $\left(X^{\prime \prime}, d^{\prime \prime}\right)$ is compact. From Lemma 3 it follows that $k\left(X^{\prime}, d^{\prime}\right)=k\left(X^{\prime \prime}, d^{\prime \prime}\right)$. From Theorem $\mathrm{A}$ we deduce $k\left(X^{\prime \prime}, d^{\prime \prime}\right) \geqq \operatorname{dim} X^{\prime \prime}$. Combining the above results, we infer $k(X, d) \geqq$ $\operatorname{dim} X^{\prime \prime}$.

What is left to prove, is that $\operatorname{dim} X^{\prime \prime} \geqq n$. So suppose $\operatorname{dim} X^{\prime \prime} \leqq n-1$. Then there is an open cover $\mathscr{W}=\left\{W_{1}, \cdots, W_{s}\right\}$ (consisting of cozerosets) such that ord $\mathscr{W} \leqq n$ and $d^{\prime \prime}$-diam $W_{i}<\delta$ for $1 \leqq i \leqq s$. Then $\left\{\phi^{-1}\left(W_{i}\right) \mid 1 \leqq i \leqq s\right\}$ is a refinement of $\mathscr{C}$, consisting of cozerosets, with order $\leqq n$. This is a contradiction. Thus $k(X, d) \geqq \operatorname{dim} X^{\prime \prime} \geqq n$, which completes the proof of Lemma 4 .

Next we will prove: $k(X) \leqq \operatorname{dim} X$. If $\operatorname{dim} X=\infty$, we have nothing to prove. So suppose $\operatorname{dim} X=n<\infty$.

Then the result will follow from

Lemma 5. Let $d_{0} \in \mathscr{R}$, and $\varepsilon_{0}>0$. Then there exists $d \in \mathscr{R}$, $d \succ d_{0}$, such that $k(X, d) \leqq n+\varepsilon_{0}$.

Proof. First we prove the following

Claim. There exist $d^{*} \in \mathscr{R}, d^{*}>d_{0}$, and $\mathscr{F}_{k}=\left\{F_{1}^{k}, \cdots, F_{m_{k}}^{k}\right\}$ $(k \geqq 0)$ such that

(i) $\mathscr{F}_{k}$ is a cover and ord $\mathscr{F}_{k} \leqq n+1 \quad(k \geqq 0)$

(ii) $d^{*}$-diam $F_{i}^{k} \leqq 1 / k \quad\left(k \in N, 1 \leqq i \leqq m_{k}\right)$

(iii) For every $\mathscr{F}^{\prime} \subset \mathscr{F}_{k}$ with $\cap \mathscr{F}^{\prime}=\varnothing$, the cover $\left\{X \backslash F \mid F \in \mathscr{F}^{\prime}\right\}$ is $d^{*}$-uniform $\quad(k \in N)$. 
Proof of Claim. We will construct inductively sequences $\left(d_{k}\right)_{k=0}^{\infty}$ of elements of $\mathscr{R}$ and $\left(\mathscr{F}_{k}\right)_{k=0}^{\infty}$ of cozero covers of $X$ in the following way: $d_{0}$ is given, put $\mathscr{F}_{0}=\{X\}$; let $k \in N$, and suppose $d_{0}, \cdots, d_{k-1}$ and $\mathscr{F}_{0}, \cdots, \mathscr{F}_{k-1}$ have been defined in such a way that

(a) $\mathscr{F}_{l}=\left\{F_{1}^{l}, \cdots, F_{m_{l}}^{l}\right\}$ is a cover and ord $\mathscr{F}_{l} \leqq n+1(0 \leqq l<k)$

(b) $\left(d_{0}+\cdots+d_{l-1}\right)$-diam $F_{i}^{l}<1 / l \quad\left(0<l<k, 0 \leqq i \leqq m_{l}\right)$

(c) For every $\mathscr{F}^{\prime} \subset \mathscr{F}$ such that $\cap \mathscr{F}^{\prime}=\varnothing$, the cover $\left\{X \backslash F \mid F \in \mathscr{F}^{\prime}\right\}$ is $d_{l}$-uniform $(0<l<k)$

(d) $\left|d_{l}\right| \leqq 2^{-l}(0<l<k)$.

Since $d_{0}+\cdots+d_{k-1} \in \mathscr{R}$, by Lemma 2 , and since $\operatorname{dim} X=n$, there exists a cover $\mathscr{F}_{k}=\left\{F_{1}^{k}, \cdots, F_{m_{k}}^{k}\right\}$ of $X$ such that ord $\mathscr{F}_{k} \leqq n+1$ and $\left(d_{0}+\cdots+d_{k-1}\right)$-diam $F_{i}^{k}<1 / k\left(1 \leqq i \leqq m_{k}\right)$ : simply take $\mathscr{F}_{k}$ to be a suitable shrinking of a finite cover $\mathscr{\mathscr { C }}=\left\{U_{1}, \cdots, U_{s}\right\}$ with ord $\mathscr{U} \leqq n+1$ and $\left(d_{0}+\cdots+d_{k-1}\right)$-diam $U_{i}<1 / k$ (compare e.g., $[1$, p. 267]).

Let $0<\delta<\min \left\{2^{-k}, \min \left\{1 / l-\left(d_{0}+\cdots+d_{k-1}\right)-\operatorname{diam} F \mid 0<l \leqq k\right.\right.$, $\left.F \in \mathscr{F}_{l}\right\}$.

Let $\left\{\mathscr{L}_{1}, \cdots, \mathscr{U}_{t}\right\}$ be the set of all covers of the form $\left\{X \backslash F \mid F \in \mathscr{F}^{\prime}\right\}$, where $\mathscr{F}^{\prime} \subset \mathscr{F}_{k}$ and $\cap \mathscr{F}^{\prime}=\varnothing$. By Lemma 1 , there exist $d^{i} \in \mathscr{R}$ such that $\left|d^{i}\right| \leqq \delta / t$ and $\mathscr{C}_{i}$ is $d^{i}$-uniform $(1 \leqq i \leqq t)$. Put $d_{k}=$ $d^{1}+\cdots+d^{t}$. It is not difficult to prove that for these choices of $\mathscr{F}_{k}$ and $d_{k}$ the conditions (a)-(d) are satisfied for $k$ instead of $k-1$. This completes the inductive construction.

Now put $d^{*}=\sum_{i=0}^{\infty} d_{i}$. By Lemma $2, d^{*} \in \mathscr{R}$. It is easy to see that $d^{*} \succ d_{0}$. The conditions (i)-(iii) are readily verified. This proves our claim.

Now, let as before $\sim$ be the equivalence relation on $X$ defined by $x \sim y$ iff $d^{*}(x, y)=0$. Let $X^{\prime}$ be the set of equivalence classes and $\phi: X \rightarrow X^{\prime}$ be projection. Let $d^{\prime}: X^{\prime} \times X^{\prime} \rightarrow[0, \infty)$ be defined by $d^{\prime}(\phi(x), \phi(y))=d^{*}(x, y)$. Again $\phi$ is continuous. Let $\left(X^{\prime \prime}, d^{\prime \prime}\right)$ be the (compact) completion of $\left(X^{\prime}, d^{\prime}\right)$. We will prove: $\operatorname{dim} X^{\prime \prime} \leqq n$. It will suffice to show that, for every $k \in N$, there exists a closed cover of $X^{\prime \prime}$ with order $\leqq n+1$ and such that its elements have $d^{\prime \prime}$-diameter not exceeding $1 / k$. So, let $k \in N$. Define $G_{i}=\operatorname{Cl}\left(\phi\left(F_{i}^{k}\right)\right)\left(1 \leqq i \leqq m_{k}\right)$, where the closure is taken in $X^{\prime \prime}$, and put $\mathscr{G}=\left\{G_{1}, \cdots, G_{m_{k}}\right\}$. Then $\mathscr{G}$ is a closed cover of $X^{\prime \prime}$, and $d^{\prime \prime}$-diam $G_{i}=d^{\prime \prime}$-diam $\phi\left(F_{i}^{k}\right)=$ $d^{\prime}$-diam $\phi\left(F_{i}^{k}\right)=d^{*}$-diam $F_{i}^{k} \leqq 1 / k$.

It is left to prove that ord $\mathscr{G} \leqq n+1$. Let $\mathscr{G}^{\prime} \subset \mathscr{G},\left|\mathscr{G}^{\prime}\right|=$ $n+2$. For convenience we assume that $\mathscr{G}^{\prime}=\left\{G_{1}, \cdots, G_{n+2}\right\}$. Let $\mathscr{F}^{\prime}=\left\{F_{1}^{k}, \cdots, F_{n+2}^{k}\right\}$. Since ord $\mathscr{F}_{k} \leqq n+1, \cap \mathscr{F}^{\prime}=\varnothing$. Thus the cover $\left\{X \backslash F_{i}^{k} \mid 1 \leqq i \leqq n+2\right\}$ is $d^{*}$-uniform and there exists $\delta>0$ such that for all $x \in X \quad U_{\delta}^{d^{*}}(x) \subset X \backslash F_{i}^{k}$ for some $i$ with $1 \leqq i \leqq n+2$.

Suppose $\cap \mathscr{G}^{\prime} \neq \varnothing$, say $z \in \cap \mathscr{G}^{\prime}$. Since $G_{i}=\operatorname{Cl}\left(\phi\left(F_{i}^{k}\right)\right)$, there exists $x_{i} \in F_{i}^{k}$ such that $d^{\prime \prime}\left(\phi\left(x_{i}\right), z\right)<\delta / 2(1 \leqq i \leqq n+2)$. Thus 
$d^{*}\left(x_{i}, x_{j}\right)=d^{\prime}\left(\phi\left(x_{i}\right), \phi\left(x_{j}\right)\right)<\delta$ for $1 \leqq i, j \leqq n+2$. It follows that $U_{\delta}^{d^{*}}\left(x_{1}\right) \cap F_{i}^{k} \neq \varnothing(1 \leqq i \leqq n+2)$, which is a contradiction. So $\cap \mathscr{G}^{\prime}=\varnothing$, and ord $\mathscr{G} \leqq n+1$. This proves $\operatorname{dim} X^{\prime \prime} \leqq n$.

Thus $\phi: X \rightarrow X^{\prime \prime}$ is a continuous map into the compact metric space $X^{\prime \prime}$, which satisfies $\operatorname{dim} X^{\prime \prime} \leqq n$. By Theorem $\mathrm{A}$, there exists a metric $d^{*}$ on $X^{\prime \prime}$ with $k\left(X^{\prime \prime}, d^{*}\right) \leqq n+\varepsilon_{0}$. Put $d(x, y)=d^{*}(\phi(x), \phi(y))$ for $x, y \in X$. From the compactness of $X^{\prime \prime}$ and the continuity of $\phi$ it follows that $d \in \mathscr{R}$. Also $d^{*} \succ d^{\prime \prime}$ on $X^{\prime \prime}$, again since $X^{\prime \prime}$ is compact. From the formulas $d^{*}(x, y)=d^{\prime \prime}(\phi(x), \phi(y))$ and $d(x, y)=$ $d^{*}(\phi(x), \phi(y))$ it follows then that $d \succ d^{*}$. Since $d^{*} \succ d_{0}$, we also have $d \succ d_{0}$. Furthermore, just as before, $k(X, d)=k\left(X^{\prime \prime}, d^{*}\right) \leqq$ $n+\varepsilon_{0}$. This completes the proof of Lemma 5 .

Combining Lemma 4 and Lemma 5, finally, we get the proof of Theorem 1.

REMARK. If $X$ is a compact, nonempty, metrizable space, then

(a) all (pseudo) metrics on $X$ are totally bounded

(b) for every two metrics $d_{1}$ and $d_{2}$, we have $d_{1}>d_{2}$

(c) for every metric $d$ and every pseudometric $d^{\prime}, d^{\prime}>d$ implies that $d^{\prime}$ is a metric, compatible with the topology.

(N. B. all these (pseudo) metrics are supposed to be continuous.)

We did prove:

$$
\operatorname{dim} X=\sup \left\{\inf \left\{k(X, d)\left|d>d_{0}, d \in \mathscr{R}\right| d_{0} \in \mathscr{R}\right\} .\right.
$$

It follows, that for fixed $d_{1} \in \mathscr{R}$

$$
\operatorname{dim} X=\sup \left\{\inf \left\{k(X, d) \mid d>d_{0}, d \in \mathscr{R}\right\} \mid d_{0}>d_{1}, d_{0} \in \mathscr{R}\right\} .
$$

(Here the fact that the pseudo-order $>$ is directed (cf. Lemma 1) is needed.) Now, if we take $d_{1}$ to be a fixed metric for $X$, we infer from (a)-(c):

$$
\begin{aligned}
\operatorname{dim} X & =\sup \left\{\inf \left\{k(X, d) \mid d>d_{0}, d \in \mathscr{R}\right\} \mid d_{0}>d_{1}, d_{0} \in \mathscr{R}\right\} \\
& =\inf \{k(X, d) \mid d \text { is a metric for } X\}
\end{aligned}
$$

which is Theorem A. Thus our result includes Theorem A as a special case.

4. The separable metrizable case. In the case of a separable metrizable space $X$ another, more direct generalization of Theorem $A$ is available. Namely, we have

THEOREM 2. Let $X$ be a nonempty, separable metrizable space. Then $\operatorname{dim} X=\inf \{k(X, d) \mid d$ is a totally bounded metric for $X\}$. 
Proof. Denote $k(X)=\inf \{k(X, d) \mid d$ is a totally bounded metric for $X$ ). First we prove: $k(X) \leqq \operatorname{dim} X$. If $\operatorname{dim} X=\infty$, we have nothing to prove. So suppose $\operatorname{dim} X=n \geqq 0$. Let $\tilde{X}$ be a metrizable compactification of $X$ with $\operatorname{dim} \tilde{X}=n[2, \mathrm{p} .65]$. Let $\varepsilon>0$ and $d_{0}$ be a metric for $\widetilde{X}$ such that $k\left(\widetilde{X}, d_{0}\right) \leqq n+\varepsilon$ (Theorem A). The restriction of $d_{0}$ to $X$ is totally bounded, and by Lemma 3 , $k\left(X, d_{0} \mid X \times X\right)=k\left(\tilde{X}, d_{0}\right) \leqq n+\varepsilon$. Thus $k(X) \leqq n=\operatorname{dim} X$.

Next we prove: $k(X) \geqq \operatorname{dim} X$. Let $d$ be any totally bounded metric for $X$. The completion $(\tilde{X}, \widetilde{d})$ of $(X, d)$ is then compact, so $k(\tilde{X}, d) \geqq \operatorname{dim} X$, again by Theorem A. By Lemma $3, k(X, d)=$ $k(\widetilde{X}, \widetilde{d})$. This completes the proof of Theorem 2 .

\section{REFERENCES}

1. R. Engelking, Outline of General Topology, North-Holland, Amsterdam, 1968.

2. W. Hurewicz and H. Wallman, Dimension Theory, Princeton, 1948.

3. M. Katětov, On the dimension of non-separable metric spaces II, Czechosl. Math.

J., (6) 81 (1956), 485-516 (Russian).

4. L. Pontrjagin and L. Schnirelmann, Sur une propriété métrique de la dimension, Ann. of Math., (2) 33 (1932), 152-162.

Received June 7, 1978 and in revised form February 20, 1979.

UNIVERSiteit VAN AMSTERDAM

Roetersstraat 15, AMsterdam 



\section{PACIFIC JOURNAL OF MATHEMATICS}

\section{EDITORS}

DONALD BABBITT (Managing Editor)

University of California

Los Angeles, CA 90024

HUGO RossI

University of Utah

Salt Lake City, UT 84112

C. C. Moore and ANDrew OGG

University of California

Berkeley, CA 94720
J. DUGUNDJI

Department of Mathematics University of Southern California Los Angeles, CA 90007

R. FINN and J. MILGRAM

Stanford University

Stanford, CA 94305

\section{ASSOCIATE EDITORS}
E. F. BeCKENBACH
B. H. NeumanN
F. WOLF
K. YOSHIDA

\section{SUPPORTING INSTITUTIONS}

UNIVERSITY OF BRITISH COLUMBIA CALIFORNIA INSTITUTE OF TECHNOLOGY UNIVERSITY OF CALIFORNIA MONTANA STATE UNIVERSITY UNIVERSITY OF NEVADA, RENO NEW MEXICO STATE UNIVERSITY OREGON STATE UNIVERSITY UNIVERSITY OF OREGON

\author{
UNIVERSITY OF SOUTHERN CALIFORNIA \\ STANFORD UNIVERSITY \\ UNIVERSITY OF HAWAII \\ UNIVERSITY OF TOKYO \\ UNIVERSITY OF UTAH \\ WASHINGTON STATE UNIVERSITY \\ UNIVERSITY OF · WASHINGTON
}

The Supporting Institutions listed above contribute to the cost of publication of this Journal, but they are not owners or publishers and have no responsibility for its content or policies.

Mathematical papers intended for publication in the Pacific Journal of Mathematics should be in typed form or offset-reproduced, (not dittoed), double spaced with large margins. Please do not use built up fractions in the text of the manuscript. However, you may use them in the displayed equations. Underline Greek letters in red, German in green, and script in blue. The first paragraph or two must be capable of being used separately as a synopsis of the entire paper. Please propose a heading for the odd numbered pages of less than 35 characters. Manuscripts, in triplicate, may be sent to any one of the editors. Please classify according to the scheme of Math. Reviews, Index to Vol. 39. Supply name and address of author to whom proofs should be sent. All other communications should be addressed to the managing editor, or Elaine Barth, University of California, Los Angeles, California, 90024.

50 reprints to each author are provided free for each article, only if page charges have been substantially paid. Additional copies may be obtained at cost in multiples of 50 .

The Pacific Journal of Mathematics is issued monthly as of January 1966. Regular subscription rate: $\$ 84.00$ a year (6 Vols., 12 issues). Special rate: $\$ 42.00$ a year to individual members of supporting institutions.

Subscriptions, orders for numbers issued in the last three calendar years, and changes of address should be sent to Pacific Journal of Mathematics, P.O. Box 969, Carmel Valley, CA 93924, U.S.A. Older back numbers obtainable from Kraus Periodicals Co., Route 100, Millwood, NY 10546.

PUBLISHED BY PACIFIC JOURNAL OF MATHEMATICS, A NON-PROFIT CORPORATION

Printed at Kokusai Bunken Insatsusha (International Academic Printing Co., Ltd.). 8-8, 3-chome, Takadanobaba, Shinjuku-ku, Tokyo 160, Japan.

Copyright (C) 1979 by Pacific Journal of Mathematics Manufactured and first issued in Japan 


\section{Pacific Journal of Mathematics}

\section{Vol. 84, No. $2 \quad$ June, 1979}

Somesh Chandra Bagchi and Alladi Sitaram, Spherical mean periodic

functions on semisimple Lie groups ........................ 241

Billy Joe Ball, Quasicompactifications and shape theory............. 251

Maureen A. Bardwell, The o-primitive components of a regular ordered permutation group ................................ 261

Peter W. Bates and James R. Ward, Periodic solutions of higher order

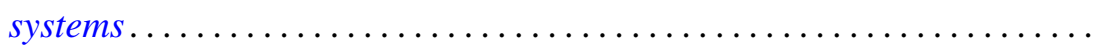

Jeroen Bruijning, A characterization of dimension of topological spaces by totally bounded pseudometrics......................... 283

Thomas Farmer, On the reduction of certain degenerate principal series

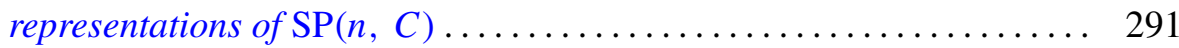

Richard P. Jerrard and Mark D. Meyerson, Homotopy with m-functions . . . . 305

James Edgar Keesling and Sibe Mardesic, A shape fibration with fibers of

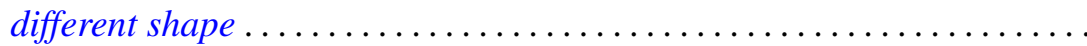

Guy Loupias, Cohomology over Banach crossed products. Application to bounded derivations and crossed homomorphisms ...............

Rainer Löwen, Symmetric planes ........................ 367

Alan L. T. Paterson, Amenable groups for which every topological left

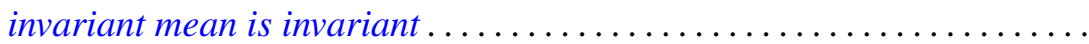

Jack Ray Porter and R. Grant Woods, Ultra-Hausdorff H-closed extensions

Calvin R. Putnam, Operators satisfying a $G_{1}$ condition .

Melvin Gordon Rothenberg and Jonathan David Sondow, Nonlinear smooth representations of compact Lie groups..............

Werner Rupp, Riesz-presentation of additive and $\sigma$-additive set-valued measures.

A. M. Russell, A commutative Banach algebra of functions of generalized variation

Judith D. Sally, Superregular sequences

Patrick Shanahan, On the signature of Grassmannians . . 